\title{
A Method of Assessing Air Toxics Concentrations in Urban Areas Using Mobile Platform Measurements
}

\author{
Vlad Isakov and Jawad S. Touma \\ National Oceanic and Atmospheric Administration, Atmospheric Sciences Modeling Division \\ (in Partnership with the U.S. Environmental Protection Agency), Research Triangle Park, NC \\ Andrey Khlystov \\ Department of Civil and Environmental Engineering, Duke University, Durham, NC
}

\begin{abstract}
The objective of this paper is to demonstrate an approach to characterize the spatial variability in ambient air concentrations using mobile platform measurements. This approach may be useful for air toxics assessments in Environmental Justice applications, epidemiological studies, and environmental health risk assessments. In this study, we developed and applied a method to characterize air toxics concentrations in urban areas using results of the recently conducted field study in Wilmington, DE. Mobile measurements were collected over a $4-\times 4-\mathrm{km}$ area of downtown Wilmington for three components: formaldehyde (representative of volatile organic compounds and also photochemically reactive pollutants), aerosol size distribution (representing fine particulate matter), and water-soluble hexavalent chromium (representative of toxic metals). These measurements were used to construct spatial and temporal distributions of air toxics in the area that show a very strong temporal variability, both diurnally and seasonally. An analysis of spatial variability indicates that all pollutants varied significantly by location, which suggests potential impact of local sources. From the comparison with measurements at the central monitoring site, we conclude that formaldehyde and fine particulates show a positive correlation with temperature, which could also be the reason that photochemically generated formaldehyde and fine particulates over the study area correlate well with the fine particulate matter measured at the central site.
\end{abstract}

\section{INTRODUCTION}

Recent public debate has focused on urban air quality, where near-source impacts are large, especially from traffic on major roadways. ${ }^{1,2}$ Our growing understanding of

\section{IMPLICATIONS}

Mobile monitoring can provide a unique capability that is not available from stationary monitor measurements. It can be used as a method to provide spatial mapping, as a diagnostic tool to supplement existing monitoring networks or to assist in siting future monitors, and it can help determine the relative importance of local versus regional impacts. the health risks for populations near major roadways and major point emission sources emphasizes the critical need to study the highly localized impacts by mapping pollutant concentration gradients in the area. Characterizing the spatial variability of air pollutants in an urban setting is critical for improved air toxics exposure assessments. 3,4 Current approaches for characterizing ambient air toxics concentrations rely on developing a detailed emissions inventory and applying a dispersion model such as AERMOD. Previous modeling studies have shown large gradients in ambient concentrations of toxic pollutants in urban areas can arise from specific stationary or mobile sources. ${ }^{5}$ However, these findings can not be verified with the widely spaced monitoring networks that currently exist in most urban areas.

To address this need, new experimental approaches are needed to provide a quick assessment of air pollutant concentration gradients, especially those arising from vehicle emission impacts. Among the most powerful approaches is the use of a mobile platform equipped with state-of-the-art, real-time, and near-real-time monitoring instruments that provide the necessary time resolution to identify high concentrations and sharp spatial gradients in an urban area.

Mobile platforms can provide a unique capability that, heretofore, has not been available with stationary monitor measurements. In addition, mobile platform measurements can establish the location where concentrations attain high levels ("hot spots") that may not be possible to find without using a large number of fixed monitors. Traditional modeling approaches are uncertain about the locations of these hot spots because of shortcomings of the emissions inventory (e.g., sources not reported in the emissions inventory) or limitations in source characterization input for the model (e.g., inability to characterize the release as a stack or fugitive source). This is especially important for air toxics assessments in Environmental Justice applications, for environmental health risk assessments, and to support epidemiological studies, in which resolving fine scale in air toxics concentrations is critical.

Another issue is the relative importance of local sources versus the contribution of regional background pollution transported into an urban area. Extensive spatial monitoring is needed to identify locations of high 
concentrations and sharp spatial gradients in urban areas. Because a mobile monitoring platform can easily traverse much of an urban area while providing fast-response measurements along its path, it can provide spatial coverage sufficient to determine both regional (background concentrations) and local impacts (superimposed signal).

Finally, mobile monitors can be used to gather data to supplement existing monitoring networks. Currently, air toxics monitoring network densities are sparse ${ }^{5}$ and the mobile monitoring data can be used as a diagnostic tool to determine spatial gradients in pollutant concentrations for multiple pollutants. This information cannot be obtained from a single monitoring station. Also, mobile measurements can help in determining the representation of existing monitoring stations and in siting future fixed monitoring locations.

A handful of research groups have developed mobile monitoring platforms using real-time instrument technologies to assess on-road and near-road air quality. Mobile monitoring measurements performed in and near Zurich, Switzerland ${ }^{6-8}$ showed that mobile measurements are useful for short-term air pollution investigations that allow distinguishing between daytime and nighttime conditions, urban and rural areas, and day-to-day variability. In the Netherlands, Weijers et al. showed an exponential decrease of concentrations as a function of distance from the road using mobile monitoring measurements. ${ }^{9}$ Weijers et al. also showed that the concentration inside a city changes on a scale of $100 \mathrm{~m}$, and that these fluctuations correlate with the local traffic intensity and driving conditions. ${ }^{9}$ In Helsinki, Finland, Pirjola et al. measured atmospheric dispersion of traffic pollutants by moving away from the highway along the wind direction. ${ }^{10}$ At a distance of 120-140 $\mathrm{m}$ from the source, the concentrations were diluted to one-tenth from the values at $9 \mathrm{~m}$ from the source.

In the United States, several real-time mobile monitoring studies have been performed. In New York City, Canagaratna et al. conducted chase vehicle studies in which on-road emissions from individual targeted vehicles were measured in real time within seconds of their emission. ${ }^{11}$ In Minneapolis, Kittelson et al. collected data under varying on-road traffic conditions in residential areas to determine the impact of highway traffic on air quality and to characterize the size and concentration of on-road aerosols on highways surrounding the Minneapolis area. ${ }^{12}$ Much lower number concentrations and larger particles were observed in residential areas located 500$700 \mathrm{~m}$ from the highway. In the Rochester-to-Buffalo interstate loop in New York, Kittelson et al. summarized the on-road aerosol and gas measurements carried out over 10 days while driving a route from Rochester to Buffalo $6 \mathrm{hr} /$ day. ${ }^{13}$ Westerdahl et al. describes the integration of multiple monitoring technologies on a mobile monitoring platform to show that average concentrations of ultrafine particles varied strongly by location, road type, and truck traffic volumes in Los Angeles. ${ }^{14}$ Also, mobile monitoring platforms have been used as a diagnostic tool to locate sulfur hexafluoride $\left(\mathrm{SF}_{6}\right)$ tracer plumes in tracer experiments in California. ${ }^{15}$

Despite these efforts, very few areas and pollutants have been studied in this way. In this paper, we present a method of providing spatially and temporally resolved distributions of toxic pollutants in urban areas. We demonstrate an application of this method using results from a recently conducted field study in Wilmington, DE. A mobile monitoring lab was used to collect a rich database for three representative pollutants: formaldehyde (representative of volatile organic compounds [VOCs] and also photochemically reactive pollutants), aerosol size distribution (representing fine particulate matter), and watersoluble hexavalent chromium (representative of toxic metals). We believe that this method shows promise and is an innovative approach to provide information necessary for spatial mapping of air toxics concentrations.

\section{AIR TOXICS MONITORING IN WILMINGTON, DE Case Study Description and Methodology}

The mobile measurements were carried out in Wilmington, DE for the Enhanced Delaware Air Toxics Assessment Study (EDATAS), which is a collaborative effort between the State of Delaware, University of Delaware, Duke University, and the United States Environmental Protection Agency (EPA). ${ }^{16}$ Wilmington was chosen for this project because of the diversity and magnitude of air pollution sources and their impacts on the community. The EDATAS project is aimed at gaining a better understanding of ambient concentrations of hazardous air pollutants throughout Delaware, as well as attaining a better assessment of exposure to those air toxics and the health risks associated with that exposure. The project is built around the existing monitoring network, but addresses the limitations of toxic sampling with the existing stationary methods, particularly the lack of temporal and spatial resolution, by implementing real-time, single-particle mass spectrometry, as well as mobile measurements of several representative air pollutants.

The Duke University research team performed the mobile measurements to provide information on the spatial distribution of pollutants throughout the city as well as variability within neighborhoods, with the spatial resolution on the order of $100 \mathrm{~m}^{16}$. The following components were measured:

- water-soluble hexavalent chromium;

- gas-phase formaldehyde; and

- aerosol number size distribution in the size range $12-270 \mathrm{~nm}$.

These components were chosen because they represent pollutants expected to have different spatial variability and different contributions from regional and secondary sources. For example, most sources of hexavalent chromium originate from localized activities such as metal plating, dye and pigment manufacturing, cleaning of various metal parts in automobiles, and the aircraft industry. ${ }^{17-19}$ Such sources are often intermittent and difficult to identify. Formaldehyde, on the other hand, has a strong contribution from photochemical reactions that add significantly to or even dominate the primary source contribution, which may make this pollutant less variable within a city. Aerosol mass, such as particulate matter (PM) less than $2.5 \mu \mathrm{m}\left(\mathrm{PM}_{2.5}\right)$, also has primary and secondary sources. Vehicular traffic is one of the main sources of PM in urban areas. Most of the particles emitted by traffic are small and are found in the ultrafine size 
range $(\leq 0.1 \mu \mathrm{m}$ in diameter). PM transported from distant sources is larger, with mean sizes around $0.3-0.5$ $\mu \mathrm{m}^{20}$. The PM from long-range sources varies slowly, with time scales ranging from hours to days. The vehicular sources, on the other hand, show strong diurnal and spatial variability. Monitoring the aerosol loading in different size ranges can be used to assess the contribution from the traffic (found mostly in the ultrafine size range), and from the long-range sources (found mostly in the accumulation mode).

\section{Measurements}

High-time resolution instruments for online measurements of the target components were installed on the Duke University minivan mobile laboratory equipped with a global positioning system (GPS). The Duke University mobile laboratory is a minivan equipped with a battery pack and a true-sine inverter that allows autonomous operation of research equipment without external power sources. An on-board GPS (Garmin GPSmap 76CS) provides the location of the vehicle as a function of time, which is logged every 5 sec. The clocks of the GPS and the on-board computers and instruments are synchronized before each run. After accounting for the delays in instrument response, the location and concentration data are matched providing concentration fields as a function of space and time. The sampling inlet was placed on an extendable mast, which is built into the van. The mast is on the left side of the vehicle, $1 \mathrm{~m}$ from the rear end. During the mobile measurements the inlet was placed at $3 \mathrm{~m}$ height. The instruments sampled through a 2-m long Teflon manifold ( $1 / 2 \mathrm{in}$. in diameter). The total flow rate through the sampling line was $23 \mathrm{~L} / \mathrm{min}$ Our calculations indicate that diffusion losses of $10 \mathrm{~nm}$ particles in our inlet are lower than 5\%, whereas losses due to image and space forces are both below 1\%. The calculations were verified by a comparison with a stationary scanning mobility particle size (SMPS) system, which showed that the two instruments agreed within 15\%. Likewise, inertial losses for the particles smaller than $2.5 \mu \mathrm{m}$ were estimated to be negligible.

Mobile measurements place a number of constraints on the instrumentation. First of all, they require a high time resolution. The average driving speed during this study was approximately 11 miles per hour (mph). To have spatial resolution of $150 \mathrm{~m}$ at such a speed the instrument should have a time resolution of $30 \mathrm{sec}$ or better. The instruments need to be sensitive enough to distinguish elevated concentrations above the background. The instruments also need to be stable during driving, i.e., have minimum interference from vibrations and acceleration/deceleration induced by the moving vehicle. All of the instruments used in this study were rigorously tested to assure the stability necessary for mobile measurements under driving conditions.

\section{Hexavalent Chromium}

The hexavalent chromium instrument was based on the method of ambient aerosol sampling. ${ }^{21}$ The instrument continuously collects ambient aerosol into liquid using a steam-jet aerosol collector (SJAC). ${ }^{22}$ The air is sampled at a rate of $16.7 \mathrm{~L} / \mathrm{min}$ through a $\mathrm{PM}_{2.5}$ cyclone (URG, Inc.).
The SJAC operates by injecting steam into the sampled airstream, which causes water vapor to condense on the sampled aerosol particles. Particles grow because of water condensation to a size of at least $1 \mu \mathrm{m}$ in diameter and are collected by a cyclone. The SJAC collects particles down to a few nanometers in diameter (collection efficiency 99\%). ${ }^{22}$ The collected liquid containing dissolved aerosol species is continuously pumped out and directed to a Long Pathlength Absorption Spectroscopy-Continuous Flow Analysis system (LPAS-CFA), where the concentration of hexavalent chromium is determined using the well established diphenycarbazide (DPC) colorimetric method.23 The detector uses a liquid core waveguide (LCW) optical cell to increase the sensitivity of the colorimetric method. The limit of detection for hexavalent chromium is $0.2 \mathrm{ng} / \mathrm{m}^{3}$. The time resolution of the instrument is $15 \mathrm{sec}$. The instrument has been regularly calibrated, including under driving conditions. ${ }^{21}$

\section{Formaldehyde}

The instrument for formaldehyde measurements was based on that described by Fan and Dasgupta, ${ }^{24}$ with several modifications. Formaldehyde is collected using continuous-flow wet-walled denuder. ${ }^{25}$ The air sample flow rate is $5.2 \mathrm{~L} / \mathrm{min}$. The airstream passes through a gap between two parallel plates that are covered with a film of flowing water. Formaldehyde dissolves in the liquid, which is continuously pumped out for analysis. The collected denuder liquid is then analyzed using the 1,3cyclohexandione fluorometric method. Instead of the flow injection analysis that was used in the Fan and Dasgupta system, we used a continuous flow analysis (CFA) system to increase the time resolution of the instrument. The other modification is the use of a fluorescence detection cell based on the LCW and made of Teflon AF (Dupont). The design of the cell follows that of $\mathrm{Li}$ et al. ${ }^{26}$ The detection limit of the instrument is $0.026 \mu \mathrm{mol} / \mathrm{m}^{3}(0.78$ $\mu \mathrm{g} / \mathrm{m}^{3}$ or $\left.0.64 \mathrm{ppbv}\right)$. The time resolution is $15 \mathrm{sec}$. The instrument was calibrated in the laboratory before the field campaigns. Multipoint calibrations were made using a semipermeable gaseous formaldehyde source (VICI Metronics). For quality assurance, single point calibrations of the analytical part of the system were performed in the field using $3.84 \mu \mathrm{M}$ standard solution of formaldehyde, which was made fresh each day.

\section{Fine PM}

Particle size distribution measurements were performed using a SMPS. ${ }^{27}$ The SMPS was built using standard parts from TSI Inc. (TSI 3071 Differential Mobility Analyzer and TSI 3010 Condensation Particle Counter). The SMPS sizes particles using an electrical mobility technique by selecting particles in a narrow mobility range, which depends on the voltage setting of the instrument. The selected particles are counted with a condensation particle counter (CPC). By performing an exponential ramping of the voltage, particles of different sizes are selected and counted, providing the number concentration as a function of size (i.e. the number size distribution). The size range of the SMPS depends on the hardware, the range of the voltage ramp, and the flow rate inside the instrument. The usual size range covered by the SMPS is from approximately 10 
to $200 \mathrm{~nm}$. It can be extended to the larger sizes (800 $\mathrm{nm})$, if lower flow rates are used, but at the expense of not sampling smaller particles. To sufficiently cover both size ranges (the ultrafine and the accumulation modes), a compromise was made in this study by setting the SMPS size range from 12 to $270 \mathrm{~nm}$. This way the SMPS covered most of the ultrafine range as well as about half of the mass distribution of the accumulation mode.

SMPS measurements were performed every minute. At the average speed of the measurements $(11 \mathrm{mph})$, 1-min sampling translates to a spatial resolution of about $300 \mathrm{~m}$. Each SMPS sample consists of one "up" and one "down" scan, each 30-sec long, and each providing information on the full size distribution. The TSI software used in this study reports only one distribution per sample. However, the SMPS can be inverted, extracting the distribution data from both up and down scans. ${ }^{27}$ This would effectively reduce the sampling interval to $30 \mathrm{sec}$.

The size distribution measured with the SMPS was used to calculate the volume concentration of the aerosol. ${ }^{28}$ The mass concentration can be calculated from the volume concentration, if the aerosol density is known. The actual particle density is rather uncertain. For example, the particle density can be lower than $1 \mathrm{~g} / \mathrm{cm}^{3}$ at locations heavily influenced by diesel traffic, ${ }^{29}$ whereas being close to $1.5 \mathrm{~g} / \mathrm{cm}^{3}$ in urban locations is less influenced by diesel emissions. ${ }^{28,30,31}$ We have chosen the value of $1.5 \mathrm{~g} / \mathrm{cm}^{3}$ for our calculations because the conditions of our study ("urban background") are similar to the study that showed that this value predicts the mass concentration within $20 \% .^{28}$

The procedure of estimating particle mass consists of calculating the integrated volume concentration from the size distribution data and multiplying it by the particle density. Because the size distribution measurements in this study spanned a range up to approximately $0.3 \mu \mathrm{m}$, we designate the derived aerosol mass as $\mathrm{PM}_{0.3}$ (analogous to $\mathrm{PM}_{2.5}$ ). As was discussed above, this size range covers most of the particulates emitted by combustion sources (which are expected to be the dominant source of PM variability in a city) as well as half of the accumulation mode, which provides us an indication of the contribution from the long-range sources.

\section{Driving Route Design and Study Schedule}

Measurements were performed while driving, and the concentrations recorded as a function of time and location. A map of the study area and locations of mobile measurements are shown in Figure 1, a and b. In these routes, the mobile van operated continuously for approximately $3 \mathrm{hr}$ in the morning and again for approximately $3 \mathrm{hr}$ in the afternoon.

The sampling involved mobile transects over a set course covering most of the street blocks over an area approximately $4 \times 4 \mathrm{~km}$ centered on downtown Wilmington. The driving route focused on mostly quiet residential streets to avoid, where possible, busier roadways. This selection was done to avoid the dominating effect of on-road emissions on the measurement results. By driving through quiet streets with little or no traffic, a more accurate assessment of the off-road concentrations could be obtained. The effect of the traffic on the concentration field can be assessed in the future by inspecting concentrations at intersections with busier streets.

Because the concentration field varies not only with place but also with time, the same route was traversed several times each day (minimum 3, typically 5-6) to obtain a reliable statistical characterization of the variability at each point and compare the mean values between different locations. Each transect took approximately $1 \mathrm{hr}$ to complete. The meteorological conditions and the atmospheric composition usually do not change significantly during $1 \mathrm{hr}$.

Mobile measurements were performed during four campaigns, one for each season (winter, spring, summer,

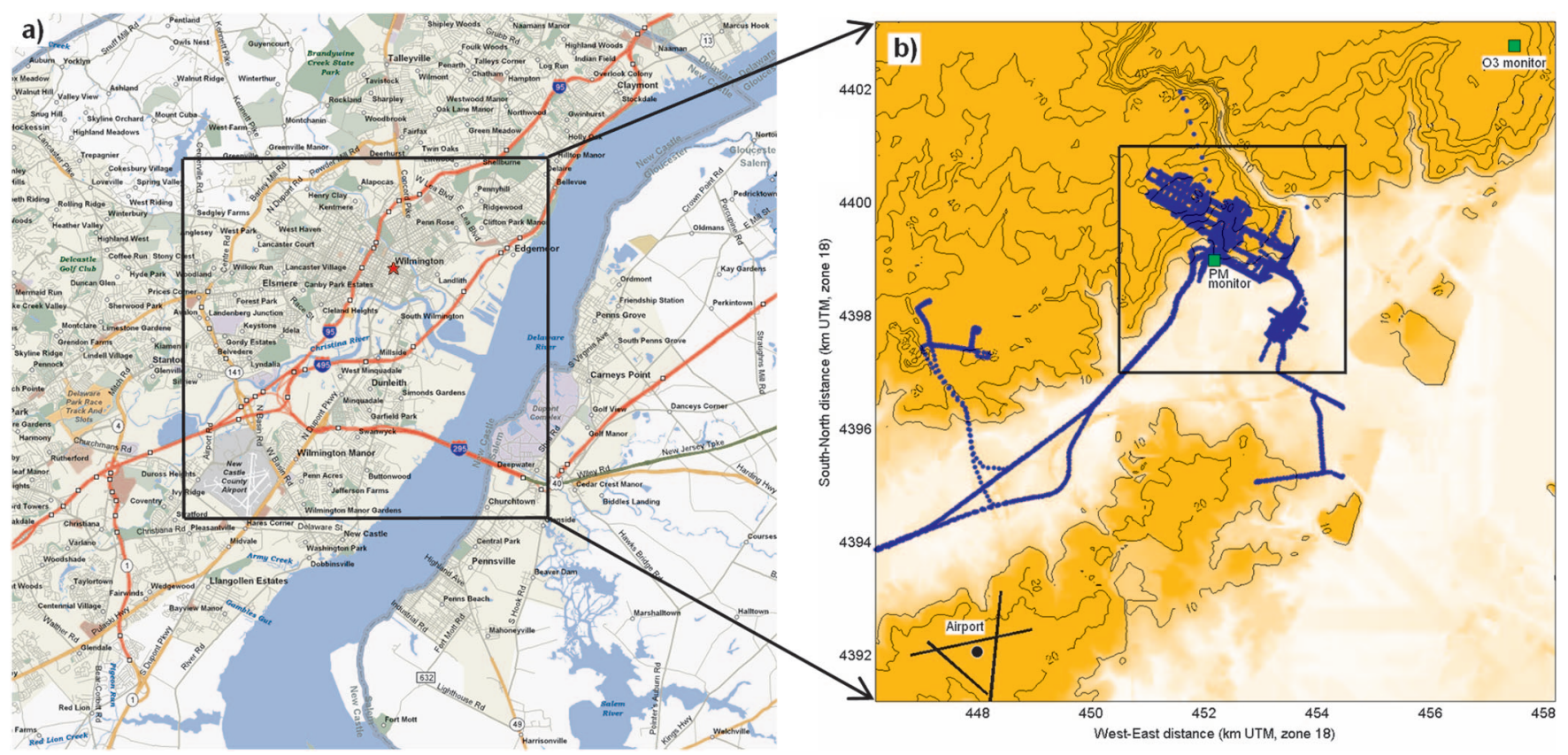

Figure 1. Map area: (a) map of in Wilmington, DE; and (b) locations of mobile measurements. 

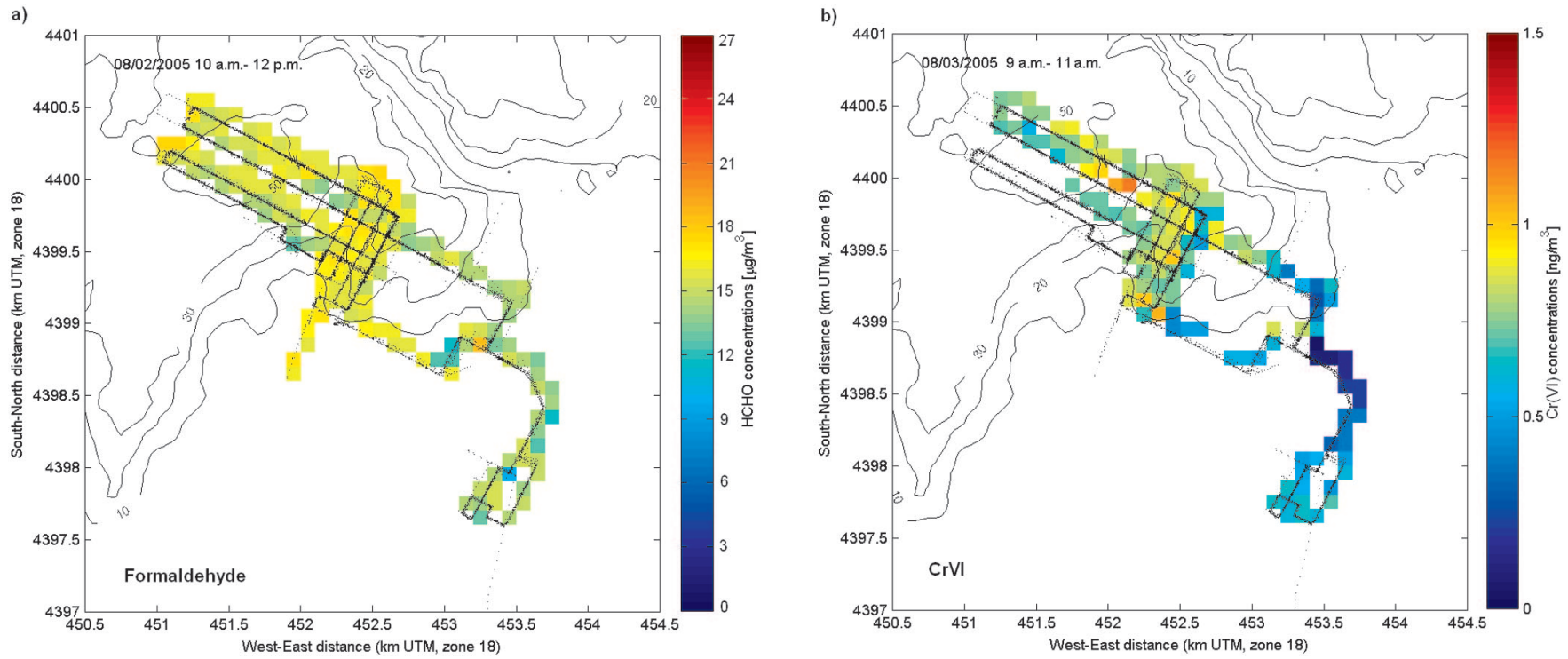

Figure 2. Examples of spatial distributions of (a) 2-hr average formaldehyde concentrations $\left(\mu \mathrm{g} \cdot \mathrm{m}^{-3}\right)$ on August 2, 2005 from $10: 00$ a.m. to 12:00 p.m; and (b) 2-hr average $\mathrm{Cr}(\mathrm{VI})$ concentrations $\left(\mathrm{ng} \cdot \mathrm{m}^{-3}\right)$ on August 3, 2005 from 9:00 a.m. to 11:00 a.m. in Wilmington, DE.

and fall), allowing characterization of the seasonal variability. The campaigns were held during the following dates:

Spring 2005: April 25-May 1

Summer 2005: July 31-August 6

Fall 2005: November 10-14

Winter 2006: February 23-26

\section{Method of Estimating Spatial and Temporal Distributions}

Mobile measurements provide a unique opportunity to estimate both spatial and temporal distributions for the area of interest. In this study, the area of intensive monitoring is approximately $4 \times 4 \mathrm{~km}$ in size in Wilmington, as indicated in Figure 1. The objective is to resolve a spatial scale down to $100 \mathrm{~m}$, so the study area would consist of $1600100-\mathrm{m}^{2}$ pixels. The mobile lab is capable of resolving spatial scale at 100- to $150-\mathrm{m}$ resolution, given its instrument response time and vehicle speed. For example, driving at an average speed of $30 \mathrm{~km}$ per hour, and using sampling interval of $15 \mathrm{sec}$, the mobile lab provides concentrations at $125-\mathrm{m}$ intervals. The van is driven multiple times through the study area to obtain multiple readings within each $100-\mathrm{m}$ area. Thus, the measurement technique provides distributions of concentrations at $100-\mathrm{m}$ resolution. These distributions then can be averaged either spatially or temporally. Short time intervals such as 1-hr are typically used to assume that the atmospheric composition does not change significantly during the specified time interval.

The mobile laboratory was equipped with a GPS. Combined with a fast-response analyzer, measured concentrations were recorded as a function of time and location $C(\mathrm{x}, \mathrm{y}, \mathrm{t})$. This combination of spatially resolved coordinates of the mobile lab and precise time was used to create spatial maps of pollutant concentrations. In this study, we averaged all the measurements that occur within each of the $100-\times 100-\mathrm{m}$ pixels for a specified time interval to create spatial maps of pollutant concentrations in Wilmington. For shorter time intervals such as hourly averages, one needs to make sure that there are a sufficient number of measurements, otherwise averaging time should be increased (i.e. 2-4 hr or more). To obtain more readings within each of the $100 \times 100$-m pixels, we have to either increase sampling frequency or reduce the size of the study area.
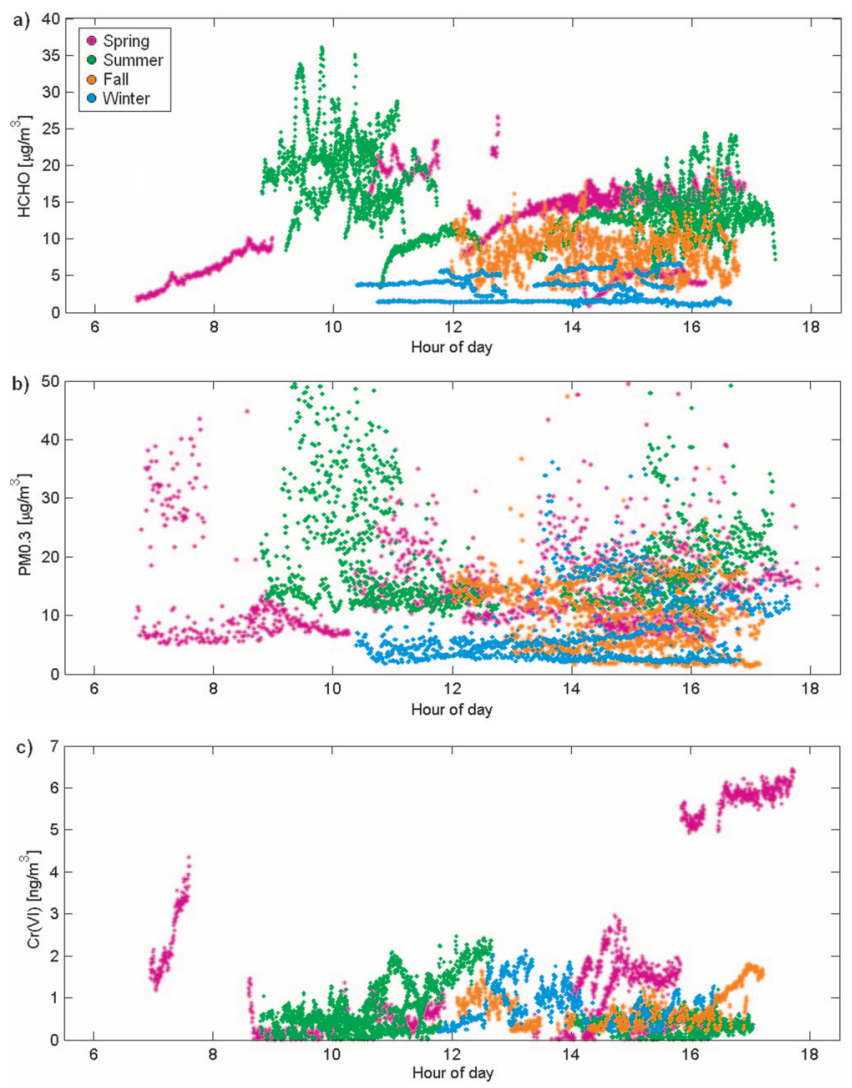

Figure 3. Diurnal distributions of observed concentrations from mobile measurements in Wilmington, DE, for three pollutants: (a) formaldehyde, (b) $\mathrm{PM}_{0.3}$, and (c) $\mathrm{Cr}(\mathrm{VI})$. 
To estimate temporal distributions, all the readings are averaged for the entire study area during a specified time period. For example, in our $4 \times 4$-km area, we took all the readings taken between 10:00 a.m. and 11:00 a.m. to obtain a 10 a.m. hourly average. To improve the representation, we computed 3-hr averages that include all measurements in the morning or in the afternoon. This approach provides the necessary information to construct a time series analysis.

\section{RESULTS}

\section{Spatial and Temporal Distributions of Air} Toxics

We applied the above method to analyze spatial and temporal distributions of formaldehyde, $\mathrm{PM}_{\mathrm{O} .3}$, and hexavalent chromium $(\mathrm{Cr}(\mathrm{VI}))$ in Wilmington, DE. Two examples of spatial distributions are shown in Figure 2, a and $\mathrm{b}$, for formaldehyde and $\mathrm{Cr}(\mathrm{VI})$, respectively. As shown in the figures, 2-hr average formaldehyde concentrations across the city range from approximately $6 \mu \mathrm{g} / \mathrm{m}^{3}$ in the downtown area along the interstate highway I-95 corridor to approximately $11 \mu \mathrm{g} / \mathrm{m}^{3}$ in other parts of the city. Despite the existence of local emission sources, the total variability is relatively small. This relatively small degree of variability may be attributed to formaldehyde being formed as a photochemically reactive pollutant and what we see is a combination of primary contribution due to direct emissions and regional background due to secondary formation. Unlike formaldehyde, chromium is much more variable throughout the city, ranging from approximately $0.1 \mathrm{ng} / \mathrm{m}^{3}$ to more than $1 \mathrm{ng} / \mathrm{m}^{3}$ in a few hot spot areas. These hot spots are most likely because of proximity to emission sources.

Figure 3 shows distributions of all data as a function of hour of day. The data show very strong variability, both diurnally and seasonally.
In considering seasonal variability, one should keep in mind that the data collected with the mobile platform do not represent a complete season, because of the limited duration of the measurements. However, some insight can be gained by observing the concentration differences between the seasons. Formaldehyde shows a seasonal trend, with concentrations being highest during the spring and summer, whereas the winter campaign had the lowest concentrations. This trend can be explained by the strong influence of photochemical activity on formaldehyde concentration, which is strongest during the warmer months. The other pollutants, $\mathrm{PM}_{\mathrm{O} .3}$ and $\mathrm{Cr}(\mathrm{VI})$, also exhibit a strong variability. $\mathrm{PM}_{\mathrm{O} .3}$ shows a seasonal trend similar to that of formaldehyde, suggesting an effect of photochemically produced secondary aerosol on the aerosol mass. However, this trend is largely obscured by the strong variability in the data, indicating the importance of other sources that are variable in time and space.

To investigate relative importance of spatial versus temporal variability, we conducted further analyses, averaging the data spatially and temporally. For each day, we took all available measurements and constructed their distributions. This is shown in Figures 4-6 for the three pollutants. As can be seen from the figures, the shapes of the distributions for all the observations are different. Distributions for $\mathrm{PM}_{\mathrm{O} .3}$ and Chromium are skewed toward high values with longer tails beyond the 75th percentile, whereas formaldehyde concentration distribution is not. This indicated that mobile measurements are capable of capturing the high values normally unavailable at a fixed monitoring site.

Spatial distributions are presented as coefficients of variability $(\mathrm{CV})$, defined as the ratio of a standard deviation over the mean value, derived from all measurements that occur in the morning and in the afternoon for each

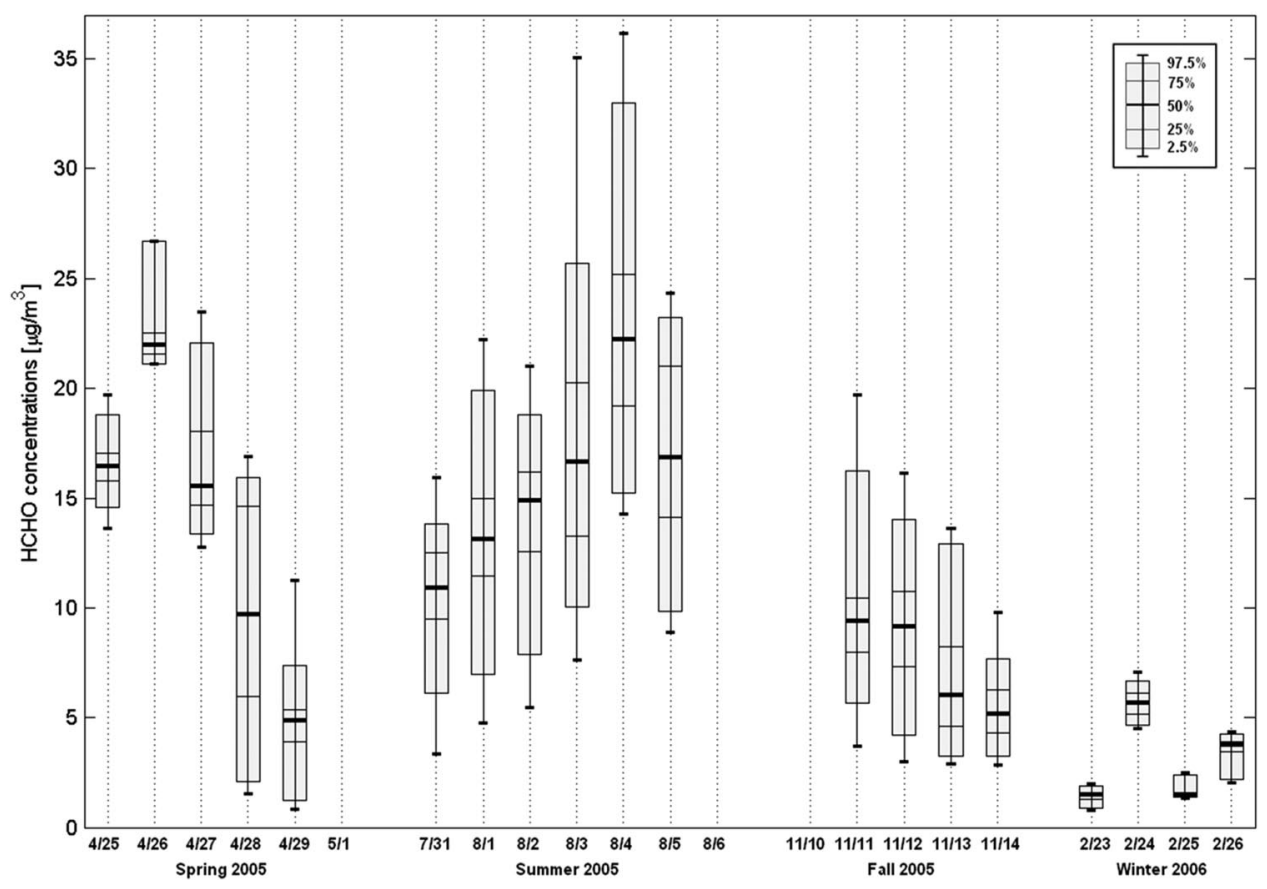

Figure 4. Distributions of formaldehyde concentrations $\left(\mu \mathrm{g} \cdot \mathrm{m}^{-3}\right)$ from mobile lab measurements in Wilmington, DE, for each day of the study using all 15 -sec average measurements. 


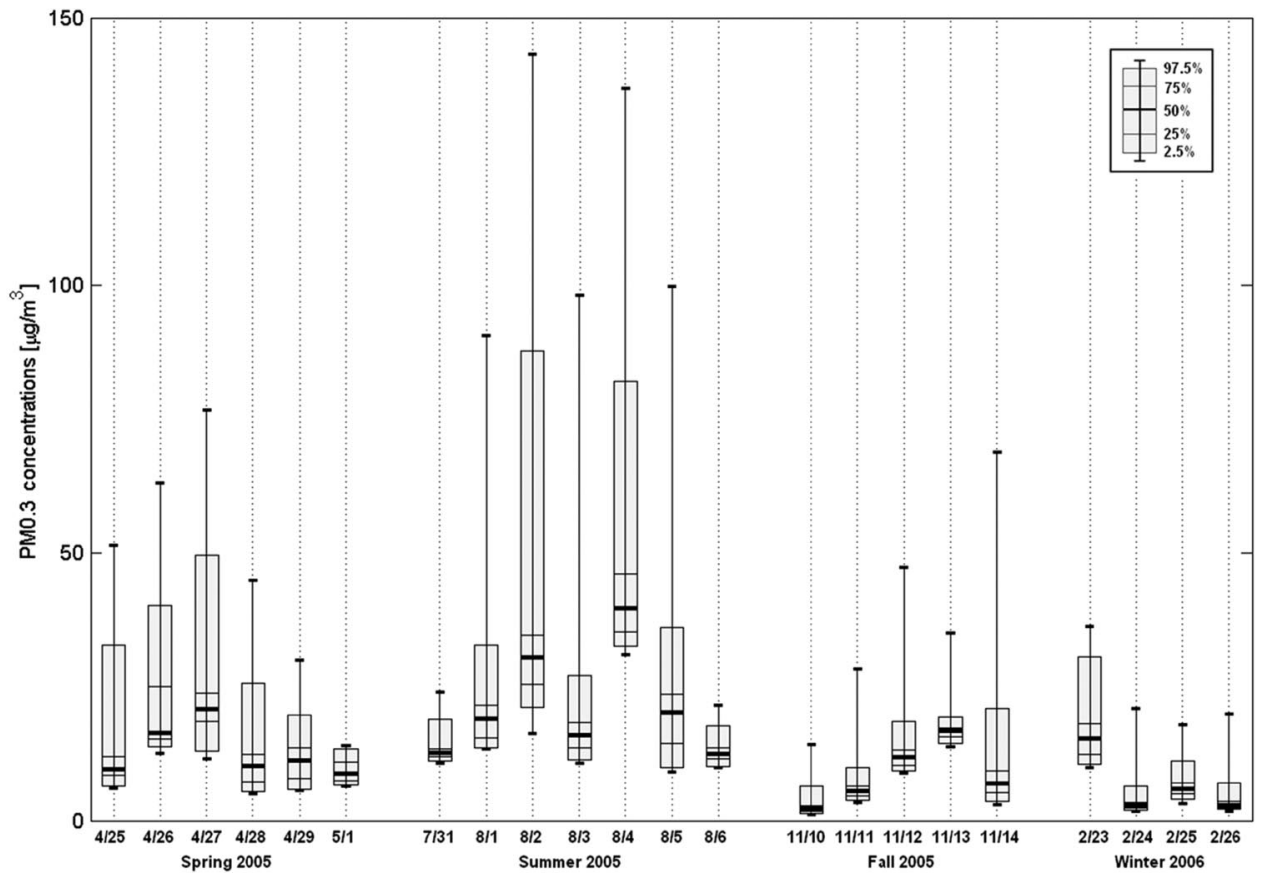

Figure 5. Distributions of $\mathrm{PM}_{0.3}$ concentrations $\left(\mu \mathrm{g} \cdot \mathrm{m}^{-3}\right)$ from mobile lab measurements in Wilmington, DE, for each day of the study using all 1-min average measurements.

day of the study period. This morning and afternoon breakdown reveals the influence of meteorological conditions. Concentrations are higher in summer in the early morning and late afternoon because of high mobile source emissions during these periods and meteorological factors such as low wind and inversion conditions. Figure 7, a and c, shows that spatial and temporal variability is much higher for $\mathrm{PM}_{\mathrm{O} .3}$ and chromium than for formaldehyde. The seasonal patterns in spatial variations for $\mathrm{PM}_{\mathrm{O} .3}$ are influenced by PM in the accumulation mode; the other two pollutants show a weak or no discernable pattern.

\section{Comparison with Central Site}

The results of the mobile measurements were compared with several of the parameters and concentrations measured at the central site of EDATAS to gain insight into the effect of some meteorological parameters, as well as to compare the average concentrations over the city with

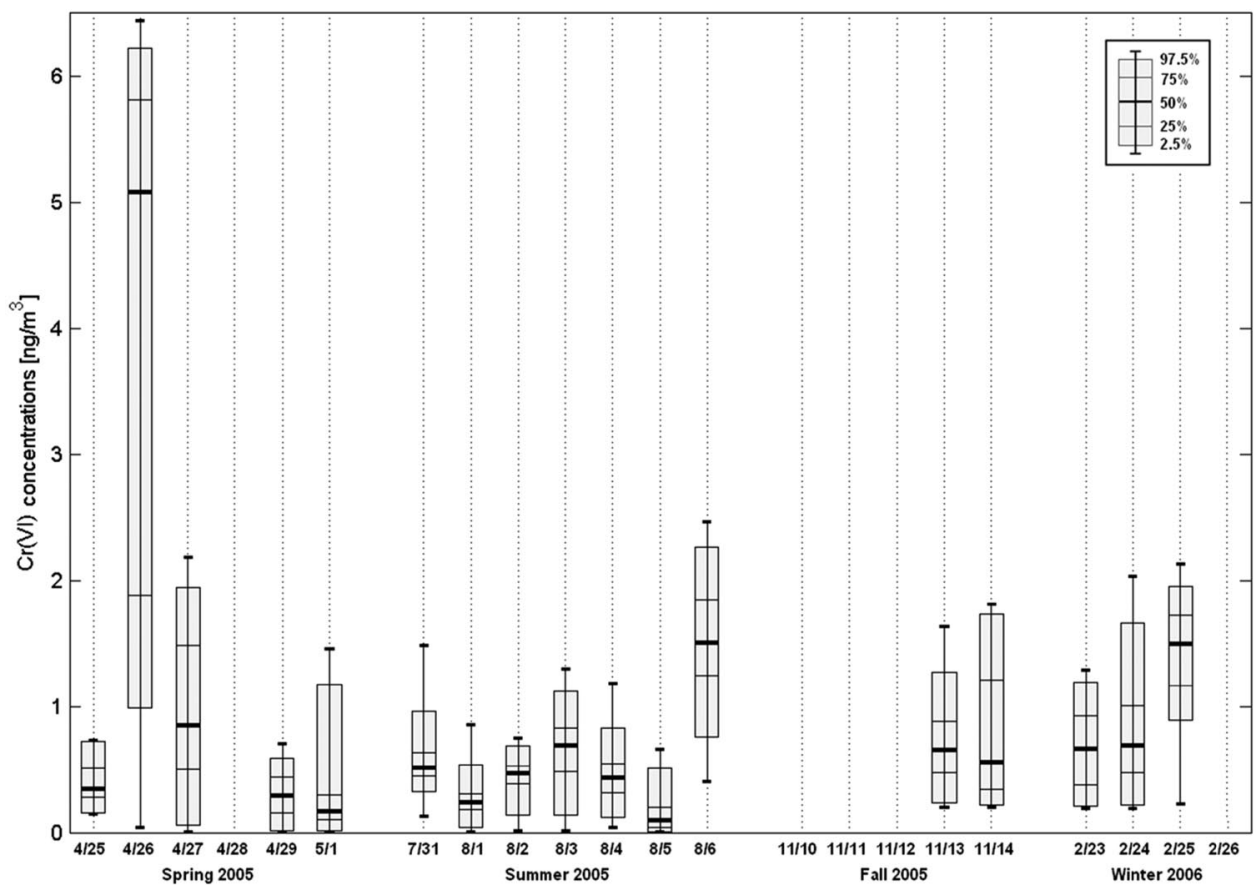

Figure 6. Distributions of $\mathrm{Cr}(\mathrm{VI})\left(\mathrm{ng} \cdot \mathrm{m}^{-3}\right)$ from mobile lab measurements in Wilmington, $\mathrm{DE}$, for each day of the study using all 15 -sec average measurements. 
a)

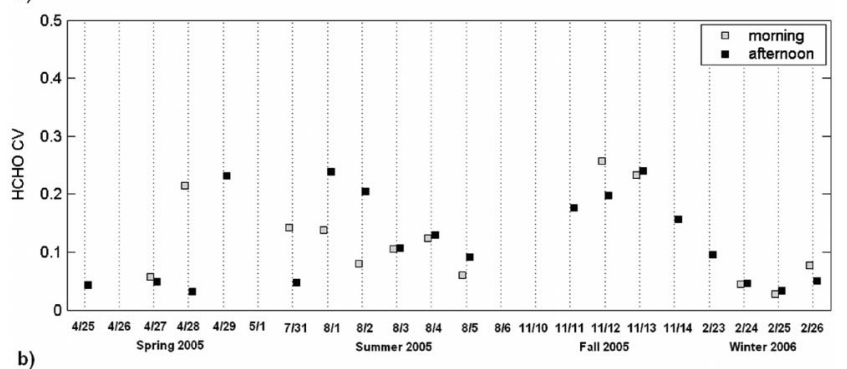

b)

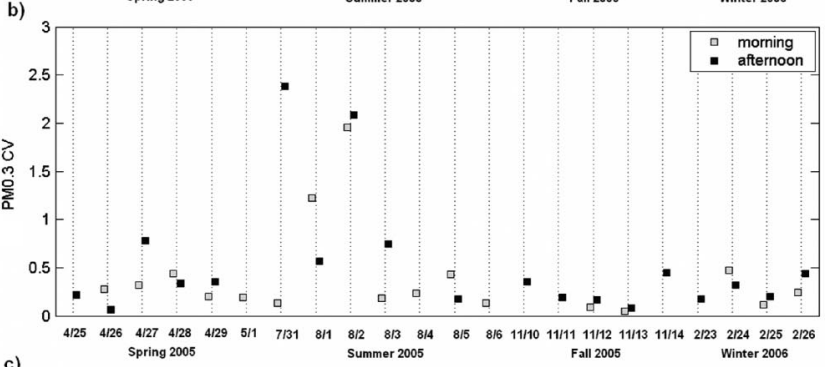

c)

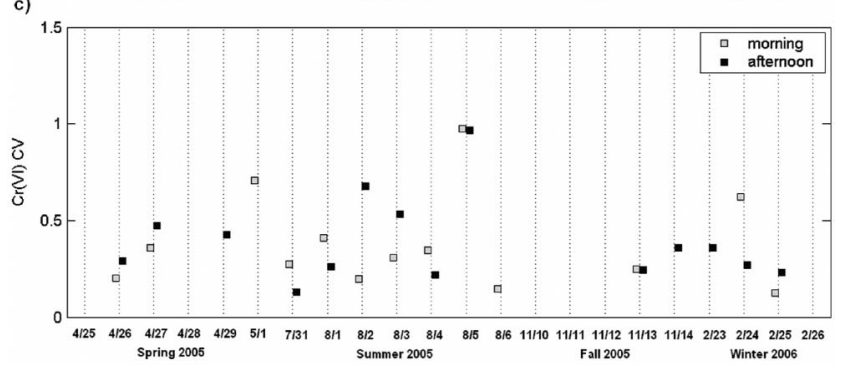

Figure 7. $\mathrm{CV}$ (in fractional units) for (a) formaldehyde, (b) $\mathrm{PM}_{0.3}$, and (c) $\mathrm{Cr}(\mathrm{VI})$ in the morning and in the afternoon for each day of the study period.

the concentrations of traffic-related pollutants measured at the central site. The location of the Martin Luther King Jr. (MLK) central site is shown in Figure 1b. For each day, the data collected at the monitoring site were averaged over the period corresponding to the time of the mobile measurements. These "daily" averages are then compared with the spatially and temporally averaged concentrations measured with the mobile platform during the corresponding days.

Figure 8 shows a comparison of mobile measurements of formaldehyde, $\mathrm{PM}_{\mathrm{O} .3}$, and $\mathrm{Cr}(\mathrm{VI})$ concentrations with ambient temperature at the central monitoring site. Formaldehyde and $\mathrm{PM}_{\mathrm{O} .3}$ exhibit a positive correlation with the temperature, suggesting again an effect of the photochemical activity. In contrast, there is no correlation between the temperature and $\mathrm{Cr}(\mathrm{VI})$ concentrations because chromium is released from primary emissions instead of secondary transformations.

Figure 9 shows a comparison of mobile measurements of formaldehyde, $\mathrm{PM}_{\mathrm{O} .3}$, and $\mathrm{Cr}(\mathrm{VI})$ concentrations with $\mathrm{PM}_{2.5}$ concentrations measured at the central cite. As can be seen from the figure, both formaldehyde and $\mathrm{PM}_{0.3}$ measurements from the mobile monitor correlate well with the $\mathrm{PM}_{2.5}$ measured at the central site. However, chromium doesn't show any correlation. Because both $\mathrm{PM}_{\mathrm{O} .3}$ and formaldehyde are correlated with $\mathrm{PM}_{2.5}$ at the central site, this suggests an effect of photochemically produced secondary aerosol and possible influence of long-range transport for these pollutants.

\section{CONCLUSIONS}

Air quality models suggest the existence of strong spatial gradients of air toxics concentrations in urban areas. ${ }^{32}$ It is difficult to verify these gradients with currently established fixed monitoring networks. This study shows the possible utility of using mobile laboratories to characterize concentration distributions and gradients in urban areas.

In this study, we have demonstrated that mobile monitoring is a useful tool for spatial mapping of toxic air pollutants in urban areas. Mobile measurements were performed in Wilmington, DE, for three pollutants-formaldehyde (representative of VOCs), $\mathrm{PM}_{\mathrm{O} .3}$ (representative of fine PM), and $\mathrm{Cr}(\mathrm{VI})$ (representative of metals). These measurements were used to construct spatial and temporal distribution for these pollutants.

In examining the distribution of observed concentrations from the mobile lab measurements, we found that the distributions for $\mathrm{PM}_{\mathrm{O} .3}$ and chromium concentrations appear to be skewed toward high values whereas formaldehyde concentration distribution is not, which indicates that $\mathrm{PM}_{\mathrm{O} .3}$ and chromium concentrations showed a higher degree of spatial variation than formaldehyde. This is consistent with other observations of formaldehyde, which is a mobile driven, highly reactive, and generally uniformly distributed pollutant and suggests that mobile measurements are capable of providing realistic results.
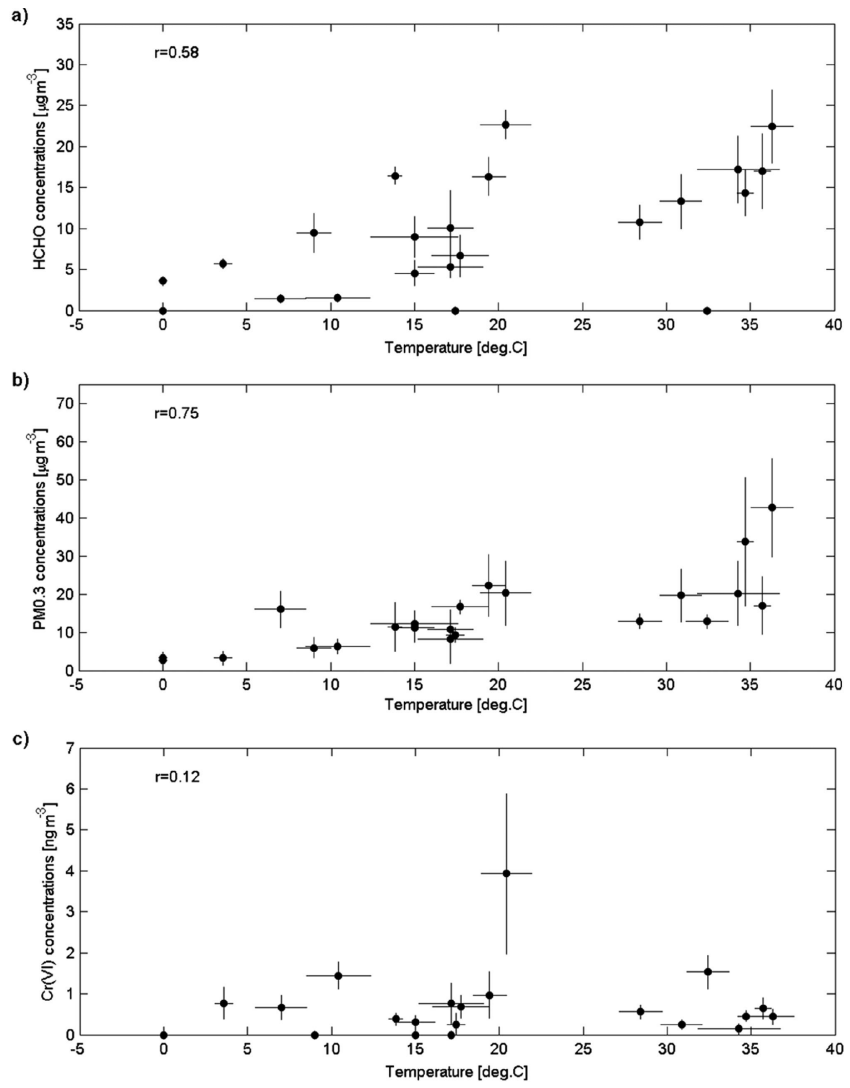

Figure 8. Correlation between mobile measurements and ambient temperature at the MLK central site in Wilmington, DE, for (a) formaldehyde $\left(\mu \mathrm{g} \cdot \mathrm{m}^{-3}\right)$, (b) $\mathrm{PM}_{0.3}\left(\mu \mathrm{g} \cdot \mathrm{m}^{-3}\right)$, and (c) $\mathrm{Cr}(\mathrm{VI})\left(\mathrm{ng} \cdot \mathrm{m}^{-3}\right)$. 


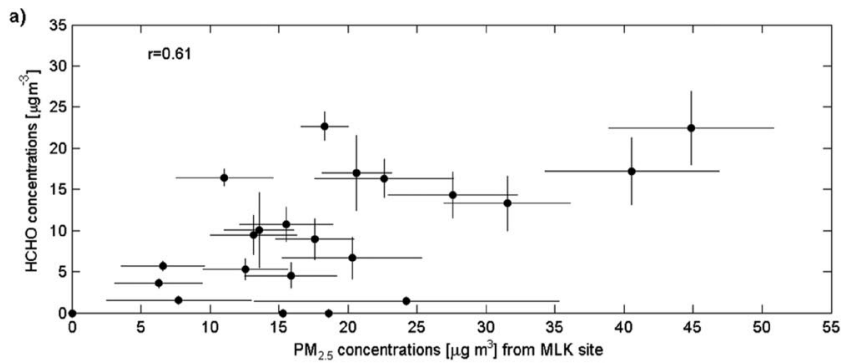

b)

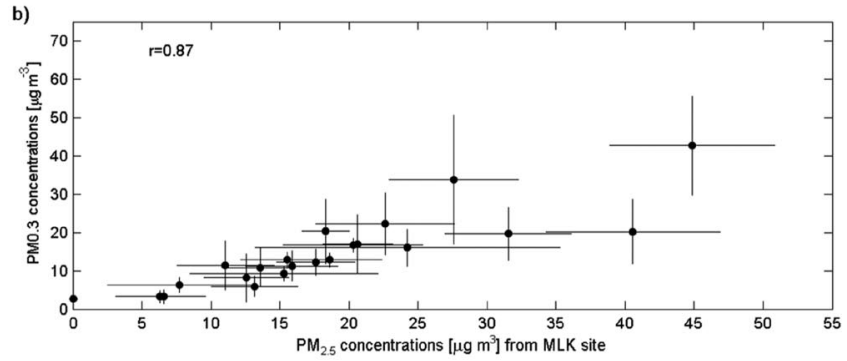

c)

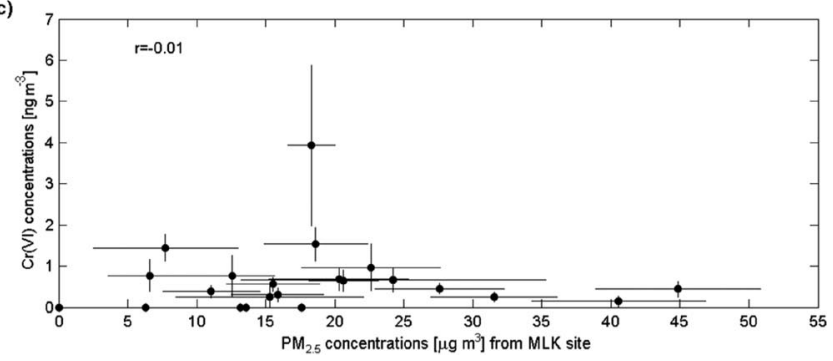

Figure 9. Correlation between mobile measurements and $\mathrm{PM}_{2.5}$ concentration at the MLK central site in Wilmington, DE, for (a) formaldehyde $\left(\mu \mathrm{g} \cdot \mathrm{m}^{-3}\right)$, (b) $\mathrm{PM}_{0.3}\left(\mu \mathrm{g} \cdot \mathrm{m}^{-3}\right)$, and (c) $\mathrm{Cr}(\mathrm{VI})$ $\left(\mathrm{ng} \cdot \mathrm{m}^{-3}\right)$.

From the comparison with measurements at the central monitoring site, we conclude that formaldehyde and $\mathrm{PM}_{\mathrm{O} .3}$ both correlate well with the $\mathrm{PM}_{2.5}$ measured at the central site. Also, both show a positive correlation with temperature, suggesting the importance of secondary production of formaldehyde and $\mathrm{PM}_{0.3}$. We found that concentrations of $\mathrm{PM}_{0.3}$ and $\mathrm{Cr}(\mathrm{VI})$ are highly variable in this urban area.

Mobile laboratories provide several advantages over fixed continuous monitoring networks by providing measurements on a quick response basis over a large part of an urban area. These measurements are also useful for identifying the presence of non-inventoried sources by placing fixed monitors near likely impact areas and selecting pollutants that are likely to have ambient impacts. Here we described an innovative approach to provide information necessary for multiplepollutant investigations that are essential for community-based assessments. We consider this innovative approach as a supplemental tool to the existing monitoring programs because mobile platform measurements do not yet have a long history of extensive quality checks, and there is no federal reference method for these measurements; thus there is a need for further evaluation of these measurement techniques for regulatory applications.

\section{ACKNOWLEDGMENTS}

The study was conducted as part of the EDATAS, which was supported by EPA and partly by the Delaware Department of Natural Resources and Environmental Control (DNREC). The authors thank Joe Martini of the DNREC and Dr. Jason Ching (EPA) for helpful discussions and valuable comments. Dr. Yilin Ma and Nitin Goel (Duke) are acknowledged for their invaluable contributions to the data collection and data analysis.

Disclaimer: The research presented here was performed under the Memorandum of Understanding between the EPA and the U.S. Department of Commerce's National Oceanic and Atmospheric Administration and under agreement number DW13921548. This work constitutes a contribution to the NOAA Air Quality Program. It does not necessarily reflect Agency policies or views.

\section{REFERENCES}

1. Chow, J.C.; Watson, J.G.; Mauderly, J.L.; Costa, D.L.; Wyzga, R.E.; Vedal, S.; Hidy, G.M.; Altshuler, S.L.; Marrack, D.; Heuss, J.M.; Wolff, G. T. Critical Review Discussion-Health Effects of Fine Particulate Air Pollution: Lines that Connect; J. Air \& Waste Manage. Assoc. 2006, 56, 1368-1380.

2. Brunekreef, B.; Holgate, S.T. Air Pollution and Health; Lancet 2002, $360,1233-1242$.

3. Isakov, V.; Graham, S.; Burke, J.; Özkaynak, H. Linking Air Quality and Exposure Modeling; EM 2006, September, 26-29.

4. Touma, J.S.; Isakov, V.; Ching, J.; Seigneur, C. Air Quality Modeling of Hazardous Pollutants: Current Status and Future Directions; J. Air \& Waste Manage. Assoc. 2006, 56, 547-558.

5. Touma, J.S.; Cox, W.M.; Tikvart, J.A. Spatial and Temporal Variability of Ambient Air Toxics Data; J. Air \& Waste Manage. Assoc. 2006, 56, 1716-1725.

6. Bukowiecki, N.; Dommen, J.; Prévôt, A.S.H.; Richter, R.; Weingartner, E.; Baltensperger, U. A Mobile Pollutant Measurement LaboratoryMeasuring Gas Phase and Aerosol Ambient Concentrations with High Spatial and Temporal Resolution; Atmos. Environ. 2002, 36, 55695579.

7. Bukowiecki, N.; Kittelson, D.B.; Watts, W.F.; Burtscher; H.; Weingartner, E.; Baltensperger, U. Real-Time Characterization of Ultrafine and Accumulation Mode Particles in Ambient Combustion Aerosols; $J$. Aerosol Sci. 2002, 33, 1139-1154.

8. Bukowiecki, N.; Dommen, J.; Prévôt, A.S.H.; Richter, R.; Weingartner, E.; Baltensperger, U. Fine and Ultrafine Particles in the Zurich (Switzerland) Area Measured with a Mobile Laboratory: an Assessment of the Seasonal and Regional Variation throughout a Year; Atmos. Chem. Phys. 2003, 3, 1477-1494.

9. Weijers, E.P.; Khlystov, A.Y.; Kos, G.P.A.; Erisman, J.W. Variability of Particulate Matter Concentrations along Roads and Motorways Determined by a Moving Measurement Unit; Atmos. Environ. 2004, 38, 2993-3002.

10. Pirjola, L.; Parviainen, T.; Hussein, T.; Valli, A.; Hämeri, K.; Aaalto, P.; Virtanen, A.; Keskinen, J.; Pakkanen, T.A.; Mäkelä, T.; Hillamo, R.E. "Sniffer"-a Novel Tool for Chasing Vehicles and Measuring Traffic Pollutants; Atmos. Environ. 2004, 38, 3625-3635.

11. Canagaratna, M.R.; Jayne, J.T.; Ghertner, D.A.; Herndon, S.; Shi, Q.; Jimenez, J.L.; Silva, P.J.; Williams, P.; Lanni, T.; Drewnick, F.; Demerjian, K.L.; Kolb, C.E.; Worsnop, D.R. Chase Studies and Particulate Emissions from In-Use New York City Vehicles; Aerosol Sci. Technol. 2004, 38, 555-573.

12. Kittelson, D.B.; Watts; W.F.; Johnson, J.P. Nanoparticle Emissions on Minnesota Highways; Atmos. Environ. 2004, 38, 9-19.

13. Kittelson, D.B.; Watts, W.F.; Johnson, J.P.; Remerowki, M.L.; Ische, E.E.; Oberdörster, G.; Gelein, R.M.; Elder, A.; Hopke, P.K.; Kim, E.; Zhao, W.; Zhou, L.; Jeong, C.H. On-Road Exposure to Highway Aerosols. 1. Aerosol and Gas Measurements. Inhal. Toxicol. 2004, 16, 31-39.

14. Westerdahl, D.; Fruin, S.; Sax, T.; Fine, P.; Sioutas, C. Mobile Platform Measurements of Ultrafine Particles and Associated Pollutant Concentrations on Freeways and Residential Streets in Los Angeles; Atmos. Environ. 2005, 39, 3597-3610.

15. Venkatram, A.; Isakov, V.; Pankratz, D.; Heumann, J.; Yuan, J. The Analysis of Data from an Urban Dispersion Experiment; Atmos. Environ. 2004, 38, 3647-3659.

16. Enhanced Delaware Air Toxics Assessment Study (EDATAS), Project Report by Delaware Natural Resources and Environmental Conservation to EPA Region 3, September 2006; available at State of Delaware Web site, http://www.awm.delaware.gov/Info/DATASForums.htm (accessed 2007). 
17. Carlton, G.N. Hexavalent Chromium Exposures during Full-Aircraft Corrosion Control; AIHA J. 2003, 64, 668-672.

18. Paustenbach, D.J.; Rinehart, W.E.; Sheehan, P.J. The Health-Hazards Posed by Chromium-Contaminated Soils in Residential and Industrial-Areas-Conclusions of an Expert Panel; Reg. Toxicol. Pharmacol. 1991, 13, 195-222.

19. Wang, J.; Ashley, K.; Marlow, D.; England, E.C.; Carlton, O. Field Method for the Determination of Hexavalent Chromium by Ultrasonication and Strong Anion Exchange Solid Phase Extraction; Anal. Chem. 1999, 71, 1027-1032.

20. Seinfeld, J.H.; Pandis, S.N. Atmospheric Chemistry and Physics: from Air Pollution to Climate Change. John Wiley \& Sons: New York, 1998.

21. Khlystov, A.; Ma, Y. An On-Line Instrument for Mobile Measurements of the Spatial Variability of Hexavalent and Trivalent Chromium in Urban Air; Atmos. Environ. 2006, 40, 8088-8093.

22. Khlystov, A.; Wyers; G.P.; Slanina; J. The Steam-Jet Aerosol Collector; Atmos Environ. 1995, 29, 2229-2234.

23. Allen, T.L. Microdetermination of Chromium with 1,5-Diphenylcarbohydrazide; Anal. Chem. 1958, 30, 447-450.

24. Fan, Q.; Dasgupta, P.K. Continuous Automated-Determination of Atmospheric Formaldehyde at the Parts-per-Trillion Level; Anal. Chem. 1994, 66, 551-556.

25. Simon, P.K.; Dasgupta, P.K.; Vecera, Z. Wet Effluent Denuder Coupled Liquid Ion Chromatography Systems; Anal. Chem. 1991, 63, 12371242.

26. Li, Q.Y.; Morris, K.J.; Dasgupta, P.K.; Raimundo, I.M.; Temkin, H. Portable Flow-Injection Analyzer with Liquid-Core Waveguide-Based Fluorescence, Luminescence, and Long Path Length Absorbance Detector; Anal. Chim. Acta 2003, 479, 151-165.

27. Wang, S.C.; Flagan, R.C. Scanning Electrical Mobility Spectrometer; Aerosol Sci. Technol. 1990, 13, 230-240.

28. Khlystov, A. Stanier, C.; Pandis, S. An Algorithm for Combining Electrical Mobility and Aerodynamic Size Distributions Data when Measuring Ambient Aerosol; Aerosol Sci. Technol. 2004, 38S, 229-238.

29. Geller, M.; Biswas, S.; Sioutas, C. Determination of Particle Effective Density in Urban Environments with a Differential Mobility Analyzer and Aerosol Particle Mass Analyzer; Aerosol Sci. Technol. 2006, 40, 709-723.

30. Tuch, Th.; Brand, P.; Wichmann, H.E.; Heyder, J. Variation of Particle Number and Mass Concentration in Various Size Ranges of Ambient Aerosols in Eastern Germany; Atmos. Environ. 1997, 31, 4193-4197.

31. Hand, J.L.; Kreidenweis, S.M. A New Method for Retrieving Particle Refractive Index and Effective Density from Aerosol Size Distribution Data; Aerosol Sci. Technol. 2002, 36, 1012-1026.

32. Isakov, V.; Venkatram, A. Resolving Neighborhood Scale in Air Toxics Modeling: a Case Study in Wilmington, California; J. Air \& Waste Manage. Assoc. 2006, 56, 559-568.

\section{About the Authors}

Vlad Isakov is a physical scientist and Jawad S. Touma is a meteorologist with the National Oceanic and Atmospheric Administration, Atmospheric Sciences Modeling Division (in Partnership with the U.S. Environmental Protection Agency), Research Triangle Park, NC. Andrey Khlystov is an assistant professor with the Department of Civil and Environmental Engineering, Duke University, Durham, NC. Please address correspondence to: Vlad Isakov, Ph.D., U.S. Environmental Protection Agency (EPA), Mail Drop E243-04, 109 T.W. Alexander Drive, Research Triangle Park, NC 27711; phone: +1-919-541-2494; fax: +1-919541-1379; e-mail: Isakov.Vlad@epa.gov. 